\title{
Cytochrome P450 3A-mediated metabolism of the topoisomerase I inhibitor 9-aminocamptothecin: Impact on cancer therapy
}

\author{
ALEXANDRA MAIER-SALAMON $^{1}$, THERESIA THALHAMMER ${ }^{2}$, GOTTFRIED REZNICEK $^{3}$, \\ MICHAELA BÖHMDORFER ${ }^{1}$, ISTVÁN ZUPKÓ ${ }^{4}$, ALEXANDER HARTL ${ }^{1}$ and WALTER JAEGER ${ }^{1}$ \\ ${ }^{1}$ Department of Clinical Pharmacy and Diagnostics, University of Vienna; ${ }^{2}$ Institute of Pathophysiology \\ and Allergy Research, Centrum for Pathophysiology and Infectiology, Medical University of Vienna; \\ ${ }^{3}$ Department of Pharmacognosy, University of Vienna, A-1090 Vienna, Austria; ${ }^{4}$ Department of \\ Pharmacodynamics and Biopharmacy, University of Szeged, Szeged 6720, Hungary
}

Received March 12, 2014; Accepted May 2, 2014

DOI: $10.3892 /$ ijo.2014.2473

\begin{abstract}
The metabolism of 9-aminocamptothecin (9-AC) was investigated in human and rat liver microsomes. In both species 9 -AC was almost exclusively biotransformed to dihydroxy-9-AC (M1) and monohydroxy-9-AC (M2). The enzymatic efficiencies of the formation of M1 and M2 $\left(\mathrm{V}_{\max } / \mathrm{K}_{\mathrm{m}}\right)$ were 1.7- and 2.7-fold higher in rat than in human liver microsomes indicating species-related differences in 9-AC hydroxylation. Incubation in the presence of human recombinant cytochrome P450 (CYP) enzymes demonstrated that the formation of M1 and M2 is mainly catalyzed by CYP3A4 and only to a minor extent by extrahepatic CYP1A1. The predominant role of CYP3A4 was further supported by a dramatic inhibition of metabolite formation in the presence of the CYP3A4 substrates troleandomycin and ketoconazole. Experiments conducted in isolated perfused rat livers further demonstrated that biliary excretion of 9-AC, M1 and M2 during $60 \mathrm{~min}$ of perfusion was pronounced and accounted for $17.7 \pm 2.59,0.05 \pm 0.01$ and $2.75 \pm 0.14 \%$ of total 9 -AC applied to the liver, respectively. In summary, this study established that CYP3A-dependent hydroxylation is the main metabolic pathway for 9-AC in rat and human liver, which have to be taken into consideration during cancer therapy of patients.
\end{abstract}

\section{Introduction}

9-Aminocamptothecin (9-amino-20[S]-camptothecin) (9-AC) is a semisynthetic derivative of camptothecin, a plant

Correspondence to: Professor Walter Jaeger, Department of Clinical Pharmacy and Diagnostics, University of Vienna, A-1090 Vienna, Austria

E-mail: walter.jaeger@univie.ac.at

Key words: 9-aminocamptothecin, hepatic metabolism, cytochrome $\mathrm{P} 450$, phase I metabolism, biliary excretion, human liver microsomes alkaloid that was isolated from the Chinese deciduous tree Camptotheca acuminata (1). Like all active camptothecins, 9-AC interferes with the nuclear enzyme topoisomerase I, which modulates several vital molecular processes, including DNA replication and recombination, RNA transcription and chromosomal decondensation. By stabilizing the cleavable complex between DNA and topoisomerase I, 9-AC traps the enzyme in a covalent reaction intermediate. This leads to single-strand breaks in the DNA, resulting in inhibition of cell proliferation, severe cell damage and ultimately cell death (2-5). In vitro studies have demonstrated that 9-AC more potently inhibits topoisomerase I than the clinically used drugs topotecan and irinotecan (6). Furthermore, in various human tumor xenografts, 9-AC was highly active even in advanced bulky tumors with minimal systemic toxicity and produced the best antitumor responses among a panel of nine anticancer agents, including 5-fluorouracil, doxorubicin, melphalan, methotrexate, vincristine, vinblastine and several nitrosourea compounds $(7,8)$.

Despite the impressive preclinical activity of $9-\mathrm{AC}$ in various cancer cell lines and tumor xenograft models, phase I/II studies showed only minor activity in various malignancies, including non-small cell lung cancer $(9,10)$, colorectal cancer $(11,12)$ and breast cancer (13), probably due to limited bioavailability of the drug. In recent years, however, studies have managed to enhance the antitumor activity of 9-AC by using copolymer conjugates for colon specific drug release (14). In addition, the use of more water soluble prodrugs, such as 9-AC-glucuronide $(15,16)$ or rubitecan (9-nitrocamptothecin) (17-19) improved the toxicity and activity of the drug in animal models and clinical trials.

Up to now, data regarding the hepatic metabolism of 9-AC is limited as only one study reported the occurrence of hepatic biotransformation products without any structural information or quantification (20). The structural analog irinotecan is inactivated by hepatic cytochrome P450 (CYP) 3A4-dependent oxidation to 7-ethyl-10-[4- $N$-(5-aminopentanoic acid)-1piperidino] carbonyloxy-camptothecin and when CYP3A4 metabolism is affected, dose modification of irinotecan has 
been shown to be necessary (21). It is therefore highly probable that $9-\mathrm{AC}$ is also subject to CYP-mediated biotransformation, resulting in lower plasma levels in patients, as impairment of 9-AC serum concentrations and increased clearance have already been observed in patients receiving hepatic enzymeinducing anticonvulsant medications (22). Therefore, the aim of the present study was to investigate the metabolism of 9-AC in rat and human livers by using liver microsomes and liver cytosol and further to identify the responsible enzymes. As the clinically used camptothecin analogs irinotecan and topotecan are preferably excreted into the bile $(23,24)$, we also wanted to investigate the biliary elimination of $9-\mathrm{AC}$ and its metabolites using the isolated perfused rat liver model.

\section{Materials and methods}

Materials. 9-AC was obtained from Santa Cruz Biotechnology (Santa Cruz, CA, USA). Uridine 5'-diphosphoglucuronic acid (UDPGA, 98-100\% purity), 3'-phosphoadenosine-5'-phosphosulfate (PAPS, 78\% purity), dithiothreitol (DTT), and the constituents for the NADPH-generating system, 7-hydroxyflavone, $\alpha$-naphtoflavone, troleandomycin and ketoconazole were obtained from Sigma (Munich, Germany). Methanol and water were of HPLC grade (Merck, Darmstadt, Germany). All the other chemicals and solvents that were used in the study were commercially available and of analytical grade. Human liver microsomes (protein content $20 \mathrm{mg} / \mathrm{ml}$ ) from one male and two females (mean age 63 years, range $45-78$ years), human liver cytosol (protein content $20 \mathrm{mg} / \mathrm{ml}$ ) from one male and two females (mean age 65 years, range 53-78 years), baculovirusinfected insect cells containing the cDNA for human CYPs 1A1, 1A2, 2A6, 2B6, 2C8, 2C9, 2C19, 2D6, 2E1 and 3A4, baculovirus-infected insect cells containing the cDNA for human flavin-containing monooyxgenase (FMO) 1, 3 and 5 were purchased from BD Biosciences (Woburn, MA, USA). The protein contents and enzyme activities of the microsomes were as described by the manufacturer. Rat liver microsomes and cytosol were prepared from three individual rat livers according to standard procedures $(25,26)$. Male Wistar rats (body weight, $233 \pm 22.5 \mathrm{~g}$; liver weight, $13.9 \pm 1.3 \mathrm{~g}$ ) were purchased from the Department of Animal Research and Genetics of the Medical University of Vienna, Austria. Animals were housed in a temperature- and humidity-controlled room under a 12-h lightdark cycle with free access to water and food. The study was approved by the Animal Experimentation Ethics Committee of the Austrian Ministry for Science and Research.

Phase I metabolism of 9-AC by rat and human liver microsomes. Incubation conditions were initially optimized for linearity of metabolite formation with respect to incubation time $(0-60 \mathrm{~min})$ and microsomal protein concentrations $(0.2-2.0 \mathrm{mg} / \mathrm{ml})$. For the subsequent assays, human and rat liver microsomes (1.0 mg protein/ml), NADPH $(1 \mathrm{mM})$, isocitric acid $(5 \mathrm{mM})$ and isocitric dehydrogenase $(0.5 \mathrm{U} / \mathrm{ml})$ were preincubated for $5 \mathrm{~min}$ at $37^{\circ} \mathrm{C}$ in $0.05 \mathrm{M}$ phosphate buffer $\mathrm{pH} 7.4$ (final volume $1.0 \mathrm{ml}$ ). The reaction was initiated by the addition of 9-AC (final concentrations: 1-20 $\mu \mathrm{M}$ ). After a 30 -min incubation at $37^{\circ} \mathrm{C}$ the reactions were terminated by adding a mixture of methanol/1 $\mathrm{M}$ phosphoric acid (96.6:3.4, $\mathrm{v} / \mathrm{v} ; 0.5 \mathrm{ml})$, the samples were centrifuged $(13000 \mathrm{x} \mathrm{g}$ for
$5 \mathrm{~min}$ ), and $100 \mu \mathrm{l}$ of the supernatant was injected onto the HPLC column. For each sample type, control experiments in the absence of NADPH were run in parallel.

Furthermore, the metabolism of 9-AC was monitored in the presence of specific CYP inhibitors, namely 7-hydroxy-flavone (CYP1A1), $\alpha$-naphthoflavone (CYP1A1 and 1A2), troleandomycin and ketoconazole (CYP3A4). After pre-incubation of the liver microsomes with the respective inhibitor $(0-100 \mu \mathrm{M})$ at $37^{\circ} \mathrm{C}$ for $3 \mathrm{~min}$ in the presence of the NADPH-generating system the reaction was initiated by the addition of 9-AC $(20 \mu \mathrm{M})$. After $30 \mathrm{~min}$ at $37^{\circ} \mathrm{C}$, the reactions were terminated and analyzed using HPLC.

Phase II metabolism of 9-AC by rat and human liver microsomes. Human and rat liver microsomes (1 mg protein $/ \mathrm{ml})$ were preincubated with alamethicin $(25 \mu \mathrm{g} / \mathrm{mg}$ protein $)$ on ice for $30 \mathrm{~min}$. Magnesium chloride $(10 \mathrm{mM})$, d-saccharic acid1,4-lactone $(5 \mathrm{mM})$, and 9-AC $(5 \mu \mathrm{M})$ were added to $50 \mathrm{mM}$ potassium phosphate buffer $(\mathrm{pH} 7.4$; total volume $=100 \mu \mathrm{l})$ and the reactions were initiated by the addition of $3 \mathrm{mM}$ UDPGA. Furthermore, human and rat liver cytosol $(5 \mathrm{mg}$ protein $/ \mathrm{ml})$ were incubated in a reaction mixture containing 9-AC $(5 \mu \mathrm{M})$, $50 \mu \mathrm{M}$ PAPS, $7.4 \mathrm{mg} / \mathrm{ml}$ DTT, $0.05 \mathrm{M}$ potassium phosphate (pH 7.4), $150 \mathrm{mM} \mathrm{KCl,} 50 \mathrm{mM}$ Tris, $\mathrm{pH} 7.5$, and 2 mM EDTA in a total volume of $100 \mu \mathrm{l}$. After 30 -min incubation at $37^{\circ} \mathrm{C}$ the reactions were stopped by adding a mixture of methanol/1 $\mathrm{M}$ phosphoric acid (96.6:3.4, v/v; $200 \mu \mathrm{l})$, samples were centrifuged (13000 x g for $5 \mathrm{~min}$ ), and $100 \mu \mathrm{l}$ of the supernatant was injected onto the HPLC column.

Metabolism of 9-AC by human CYP and FMO isoenzymes. Screening of 9-AC hydroxylation was performed using baculovirus-infected insect cells containing the cDNA for human CYP 1A1, 1A2, 2A6, 2B6, 2C8, 2C9, 2C19, 2D6, 2E1 and 3A4 and baculovirus-infected insect cells containing the cDNA for human FMO 1, 3 and 5. Supersomes (1 mg protein $/ \mathrm{ml})$ were incubated at $37^{\circ} \mathrm{C}$ with $9-\mathrm{AC}(5 \mu \mathrm{M})$ and NADPH $(1 \mathrm{mM})$ under conditions that were identical to those outlined above. Blank reactions contained buffer in the place of substrate.

Liver perfusion. The study was approved by the Animal Experimentation Ethics Committee of the Austrian Ministry for Science and Research. Livers of male Wistar rats $(n=3$; body weight, $240 \pm 10 \mathrm{~g}$; liver weight, $11.7 \pm 0.2 \mathrm{~g}$ ) were purchased from the Department of Animal Research and Genetics of the Medical University of Vienna, Austria. Single pass liver perfusion experiments were carried out using the techniques described previously (27). Total volume of the perfusion reservoir was $2500 \mathrm{ml}$. The perfusions were conducted using Krebs-Henseleit bicarbonate buffer (KHB), $\mathrm{pH} 7.4$, equilibrated with $95 \% \mathrm{O}_{2} / 5 \% \mathrm{CO}_{2}$ (flow rate $=3.1 \mathrm{ml} / \mathrm{g}$ liver.min). The temperature of the perfusion cabinet and perfusion medium was thermostatically controlled at $37^{\circ} \mathrm{C}$. Single bile drops falling from the bile duct cannula were weighed (approximately $8 \mu \mathrm{g}$ ) and collected. Bile flow was determined by the interval between drops and the liver weight and is presented as $\mu \mathrm{g} / \mathrm{g}$ liver.min. After $30 \mathrm{~min}$ of perfusion with KHB, stock solutions of 9-AC (2.5 mM in DMSO) were added such that the final concentrations were $5 \mu \mathrm{M}$ and perfusion was continued for $60 \mathrm{~min}$. The perfusion pressure was 
approximately $6 \mathrm{~cm} \mathrm{H}_{2} \mathrm{O}$ and remained constant during the control and 9-AC perfusions. To test the stability of 9-AC under perfusion conditions, control experiments were performed by applying the solution to the perfusion model in the absence of a liver. To study time-dependent first-pass metabolism, bile (30-50 $\mu \mathrm{l})$ and perfusate (approximately $1.5 \mathrm{ml}$ ) samples were collected every $5 \mathrm{~min}$ for up to $90 \mathrm{~min}$, immediately frozen on dry ice and stored at $-80^{\circ} \mathrm{C}$. Prior to analysis, the bile and perfusate samples were centrifuged (5000 x $\mathrm{g}$ for $5 \mathrm{~min}$ ). The $\mathrm{pH}$ of the bile samples was adjusted to 3.0 by the addition of acidic water (5 $\mu 1$ of supernatant plus $995 \mu \mathrm{l}$ of distilled water), and $80 \mu \mathrm{l}$ of diluted bile samples and perfusate supernatants were injected onto the HPLC column.

Determination of 9-AC and its metabolites. The quantification of 9-AC and its metabolites was performed using an UltiMate 3000 HPLC system (Dionex, Sunnyvale, CA) equipped with a Hypersil BDS-C18 column (5 $\mu \mathrm{m}, 250 \times 4.6$ mm I.D., Thermo Fisher Scientific, Inc., Waltham, MA), preceded by a Hypersil BDS-C18 precolumn (5 $\mu \mathrm{m}, 10 \times 4.6 \mathrm{~mm}$ I.D.), at a flow rate of $1 \mathrm{ml} / \mathrm{min}$ and a column temperature of $35^{\circ} \mathrm{C}$ as previously described (28). Briefly, 9-AC and its metabolites were separated using a mobile phase consisting of a continuous gradient mixed from methanol and $10 \mathrm{mM}$ ammonium acetate/acetic acid buffer $(10 \mathrm{mM}, \mathrm{pH} 5.0)$ at a flow rate of $1 \mathrm{ml} / \mathrm{min}$. The gradient ranged from $10 \%$ methanol ( $0 \mathrm{~min}$ ) to $25 \%$ methanol at $25 \mathrm{~min}$, $60 \%$ methanol at $40 \mathrm{~min}$, was kept constant at $60 \%$ until $45 \mathrm{~min}$ and finally decreased linearly to $10 \%$ at $47 \mathrm{~min}$. The columns were allowed to re-equilibrate for $20 \mathrm{~min}$ between runs. Quantification of 9-AC and its metabolites was monitored at an excitation of $365 \mathrm{~nm}$ and an emission of $440 \mathrm{~nm}$. Calibration of the chromatogram was accomplished using the external standard method with standard solutions of 9-AC to obtain a concentration range from 0.05 to $10 \mu \mathrm{g} / \mathrm{ml}$ (average correlation coefficients, $>0.99$ ). As standards for the metabolites were not available in adequate amounts, quantification of these products was based on the assumption that the unknown metabolites had similar fluorescence intensities to 9-AC.

Identification of 9-AC metabolites. Liquid chromatography/ mass spectrometry (LC-MS/MS) analyses of human and rat liver microsomes as well as bile samples, were performed on an UltiMate 3000 RSLC-series system (Dionex, Germering, Germany) coupled to a mass spectrometer equipped with an orthogonal ESI source. Positive ion polarity was used to acquire mass spectra from $\mathrm{m} / \mathrm{z}=150-900$ in scanning mode. The metabolites M1 and M2 were further analyzed on a AB Sciex API 4000 triple quadrupol mass spectrometer using the following parameters: IS + 4100, DP 50, CUR 10, GS1 20, TEM $400^{\circ} \mathrm{C}$, scan: $\mathrm{m} / \mathrm{z} 100-1000 / \mathrm{sec}$. The HPLC column, injection volume, mobile phase, gradient, and flow rate were identical to those used for the analytical HPLC assay (see above).

Data analysis. Each experiment in the various assays was performed at least in triplicate and the results were expressed as the means $\pm \mathrm{SD}$. Because the increased hydrolysis of 9-AC (lactone) to 9-AC hydroxy acid at $\mathrm{pH} 7.4$ of the incubation medium would prevent a separation of M2 from 9-AC hydroxy acid, the $\mathrm{pH}$ of the mobile phase was set at $\mathrm{pH}$ 5.0.9-AC, M1 and M2 were therefore calculated as the total amount of their corresponding lactone and carboxylated forms. The kinetic parameters for 9-AC hydroxylation were estimated using the Prism program (version 5.0, GraphPad Software, Inc., San Diego, CA). The data were fit to the following models:

i) The Michaelis-Menten model

$$
\mathrm{V}=\mathrm{V}_{\max } \times \mathrm{S} /\left(\mathrm{K}_{\mathrm{m}}+\mathrm{S}\right)
$$

where $\mathrm{V}$ is the rate of the reaction, $\mathrm{S}$ is the substrate concentration, $\mathrm{V}_{\max }$ is the maximum enzyme velocity and $\mathrm{K}_{\mathrm{m}}$ is the Michaelis constant (the substrate concentration needed to achieve a half-maximal enzyme velocity).

ii) The Hill model (sigmoidal)

$$
\mathrm{V}=\mathrm{V}_{\max } \times \mathrm{S}^{\mathrm{n}} /\left(\mathrm{S}_{50}{ }^{\mathrm{n}}+\mathrm{S}^{\mathrm{n}}\right)
$$

where $\mathrm{V}$ is the rate of the reaction, $\mathrm{S}$ is the substrate concentration, $\mathrm{V}_{\max }$ is the maximum enzyme velocity, $\mathrm{S}_{50}$ is the substrate concentration resulting in $50 \%$ of $\mathrm{V}_{\max }$ (analogous to $\mathrm{K}_{\mathrm{m}}$ ) and $\mathrm{n}$ is the Hill coefficient (= degree of sigmoidicity).

The kinetic profiles were further analyzed using EadieHofstee plots. The coefficient of determination $\left(\mathrm{R}^{2}\right)$ and visual inspection of the Eadie-Hofstee plots were used to determine the quality of a fit to a specific model. The enzymatic efficacy, which is defined as the ratio of $\mathrm{V}_{\max } / \mathrm{K}_{\mathrm{m}}$, quantifies the hydroxylation capacity and corresponds to the intrinsic clearance.

Pharmacokinetic parameters for 9-AC and its metabolites M1 and M2 in the isolated perfused rat liver were calculated using data recorded after the steady state had been reached. Inflow and outflow molar concentrations and biliary excretion were averaged before inclusion into the following pharmacokinetic equations:

The hepatic availability $\left(\mathrm{F}_{\mathrm{H}}\right)$ of 9-AC was calculated using the following equation:

$$
F_{H}=\frac{X_{\text {out }}}{X_{\text {in }}}
$$

where $X_{\text {in }}$ is the administered dose (amount of 9-AC applied to the liver during the experiment) and $\mathrm{X}_{\text {out }}$ is the amount of 9 -AC excreted in the effluent perfusate over a 60 -min period.

The hepatic clearance $\left(\mathrm{Cl}_{\mathrm{H}}\right)$ of 9 -AC was calculated using the following equation:

$$
\mathrm{Cl}_{\mathrm{H}}=\mathrm{E} \mathrm{x} \text { perfusate flow rate }
$$

where $\mathrm{E}$ is the extraction rate $(1-\mathrm{F})$.

The amount of 9-AC and its metabolites M1 and M2 excreted into the bile during the 60 -min perfusion, expressed as a percentage of the administered dose $\left(f_{\text {bile }}\right)$, was calculated using the following equation:

$$
f_{\text {bile }}=\frac{\mathrm{X}_{\mathrm{C}} \mathrm{x} \text { bile flow } \mathrm{x} \text { liver weight } \mathrm{x} 100}{\mathrm{X}_{\mathrm{in}}}
$$

where $X_{\text {in }}$ is the administered dose and $X_{C}$ is the cumulative amount of $9-\mathrm{AC}$ and the metabolites M1 and M2 in the bile, respectively. 
The amount of 9-AC and its metabolites excreted into the perfusate during the $60 \mathrm{~min}$ of perfusion, expressed as a percentage of the administered dose $\left(f_{\text {perfusate }}\right)$, was calculated using the following equation:

$$
f_{\text {perfusate }}=\frac{\mathrm{X}_{\mathrm{C}} \times 100}{\mathrm{X}_{\mathrm{in}}}
$$

where $\mathrm{X}_{\text {in }}$ is the administered dose and $\mathrm{X}_{\mathrm{C}}$ is the cumulative amount of 9-AC and the metabolites M1 and M2 in the perfusate, respectively.

Unless otherwise indicated, values are expressed as the mean values \pm SD from three individual experiments. The differences from control values were evaluated using a paired Student's t-test, at a significance level of $\mathrm{p}<0.05$.

\section{Results}

Hepatic metabolism of 9-AC. To assess hepatic phase I and II metabolism of 9-AC, liver microsomes and cytosol from three individual human and three individual rat livers were incubated with 9-AC in the presence of NADPH, UDPGA and PAPS and subsequently analyzed using HPLC. In the presence of NADPH, in addition to unmodified 9-AC ( $\left.\mathrm{t}_{\mathrm{r}}=38.3 \mathrm{~min}\right)$, two metabolites, M1 ( $\left.\mathrm{t}_{\mathrm{r}}=21.9 \mathrm{~min}\right)$ and M2 $\left(\mathrm{t}_{\mathrm{r}}=35.4 \mathrm{~min}\right)$, could be detected in both human and rat liver. Incubations of hepatic liver microsomes and cytosol in the presence of UDPGA and PAPS, however, demonstrated that 9-AC and its phase I products are not further conjugated with either glucuronic or sulfuric acid in human and rat liver (data not shown). Structures of the metabolites M1 and M2 were further analyzed by LC-MS/MS. The spectrum of the parent drug 9-AC gave abundant protonated molecules at $\mathrm{m} / \mathrm{z} 364$ with characteristic fragmentation ions at $\mathrm{m} / \mathrm{z} 320$ and $\mathrm{m} / \mathrm{z} 355$, corresponding to the loss of $\mathrm{CO}_{2}(-44 \mathrm{amu})$ and the loss of $\mathrm{C}_{2} \mathrm{H}_{5}(-29 \mathrm{amu})$ at the lactone ring. The mass spectra of $\mathrm{M} 1$ and M2 revealed their protonated molecules at $\mathrm{m} / \mathrm{z} 396$ and $\mathrm{m} / \mathrm{z} 380$. These mass shifts of $+32 \mathrm{amu}(+2 \mathrm{OH})$ and $+16 \mathrm{amu}$ $(+1 \mathrm{OH})$ imply hydroxylation of 9-AC. As both metabolites showed identical fragmentation compared to parent compound with product ions at $\mathrm{m} / \mathrm{z} 352$ (-44 amu), m/z 367 (-29 amu) and $\mathrm{m} / \mathrm{z} 336$ (-44 amu), m/z 351 (-29 amu), respectively, structural alterations of the lactone ring can be excluded. This is further confirmed by additional $\mathrm{pH}$-experiments which showed reversible lactone/carboxylate equilibrium of the hydroxylated metabolites. To further elucidate the point of attachment of the hydroxyl groups, we investigated the formation of 9-AC metabolites by recombinant human FMO1, 3 and 5, which catalyze the oxidation of hetero-atoms, like nitrogen and sulfur, resulting in the formation of $\mathrm{N}$-oxides and S-oxides. As the formation rates of M1 and M2 by human FMO 1, 3 and 5 were below the detection limits (data not shown), we conclude that 9-AC is not hydroxylated at one of its three nitrogen moieties. The structural analog 9-nitro-camptothecin is hydroxylated in position 10 , whereby an arene ring oxide is proposed to be formed as an intermediate product (29). It is therefore most likely that 9-AC undergoes the same reaction resulting in the formation of 10-hydroxy-9-AC. However, due to insufficient amounts of the metabolites further determination of the point of attachment of the hydroxyl groups was not possible.
Hydroxylation of 9-AC in rat and human liver microsomes. Liver microsomes were incubated with 5 and $20 \mu \mathrm{M} 9-\mathrm{AC}$ in the presence of NADPH for $30 \mathrm{~min}$ and the formation of hydroxylation products of 9-AC was quantified via HPLC analysis. 9-AC hydroxylation to M1 and M2 occurred in both species, but at significantly different ratios. While in human liver microsomes $7.38 \pm 0.74 \%$ of the applied dose $(5 \mu \mathrm{M}$ 9-AC) was hydroxylated to M1 and $16.6 \pm 6.83 \%$ to M2, formation of both metabolites in rat liver was significantly higher (14.4 $\pm 5.68 \%$ for M1 and $33.5 \pm 14.7 \%$ for M2). Interestingly, when 9-AC concentration was raised to $20 \mu \mathrm{M}$, a pronounced decrease of hydroxylation in both species was observed as the formation rates of $\mathrm{M} 1$ and $\mathrm{M} 2$ were reduced by 2- to 3-fold (human: M1 3.33 $\pm 0.29 \%$ and M2 7.67 $\pm 1.65 \%$; rat: M1 $5.07 \pm 2.00 \%$ and $\mathrm{M} 212.0 \pm 4.55 \%$ of applied dose, respectively) indicating saturation of the responsible enzymes (data not shown). In both human and rat liver microsomes the formation of M1 reached steady state concentrations after 25 min of incubation with mean values of $382 \pm 59.4$ pmoles $/ \mathrm{mg}$ protein and $9862 \pm 29.2$ pmoles $/ \mathrm{mg}$ protein. Analogous the formation rates of M2 showed a plateau after 30 min with mean values of $1253 \pm 147$ pmoles/mg protein for human liver and $1637 \pm 46.3 \mathrm{pmoles} / \mathrm{mg}$ protein for rat liver.

Kinetic profiles of 9-AC hydroxylation. Using data obtained from incubations with 1-20 $\mu \mathrm{M}$ 9-AC the enzyme kinetic profiles for the formation of M1 and M2 in human and rat liver microsomes were evaluated. The most appropriate corresponding kinetic model was determined by fitting the data to the equations, as described in the materials and methods section, to obtain correlation coefficients $\left(\mathrm{R}^{2}\right)$, and by visual assessment of the Eadie-Hofstee plots (shown as insets in Fig. 3). Formation of M1 catalyzed by both human and rat microsomes exhibited a hyperbolic kinetic profile that was consistent with classical Michaelis-Menten kinetics, as characterized by a linear Eadie-Hofstee plot $\left(\mathrm{R}^{2}=0.96\right.$ and 0.98 , respectively). However, we observed significant differences in the kinetic parameters calculated for the two liver species. While $\mathrm{V}_{\max }$, the maximum enzyme velocity, was comparable in both species (human, $15.9 \pm 0.71$ pmoles/mg.min; rat, $20.9 \pm 1.98$ pmoles/mg.min), the Michaelis constant $\mathrm{K}_{\mathrm{m}}$ was approximately 2 -fold higher in human microsomes $\left(\mathrm{K}_{\mathrm{m}}=8.29 \pm 0.88 \mu \mathrm{M}\right)$ than it was in rat microsomes $\left(\mathrm{K}_{\mathrm{m}}=4.48 \pm 1.28 \mu \mathrm{M}\right)$. These differences resulted in significantly higher intrinsic clearance values in rat microsomes (human, $1.90 \pm 0.27 \mathrm{ml} / \mathrm{mg} . \mathrm{min}$; rat, $4.71 \pm 1.29 \mathrm{ml} / \mathrm{mg} . \mathrm{min}$ ), indicating interspecies differences in the metabolizing capacity for M1 formation. Table I summarizes the individual kinetic parameters for the formation of M1.

Formation of M2 in human and rat liver microsomes also followed classic Michaelis-Menten kinetics $\left(\mathrm{R}^{2}=0.98\right.$ and 0.96, respectively), as confirmed by linear Eadie-Hofstee plots (Fig. 1). Again we observed comparable $\mathrm{V}_{\max }$ values in both species (human, 34.9 44.67 pmoles/mg.min; rat, 47.2 \pm 4.44 pmoles/mg.min), concomitant with deviating $\mathrm{K}_{\mathrm{m}}$ values (human, 7.77 $\pm 2.42 \mu \mathrm{M}$; rat, 3.67 $\pm 1.11 \mu \mathrm{M}$ ). Therefore, intrinsic clearance values were considerably higher in rat liver than in the human source (human, $4.46 \pm 1.97 \mathrm{ml} / \mathrm{mg} . \mathrm{min}$; rat, 13:1 $\pm 6: 15 \mathrm{ml} / \mathrm{mg} . \mathrm{min})$. Table II summarizes the individual kinetic parameters for the formation of M2. 
A
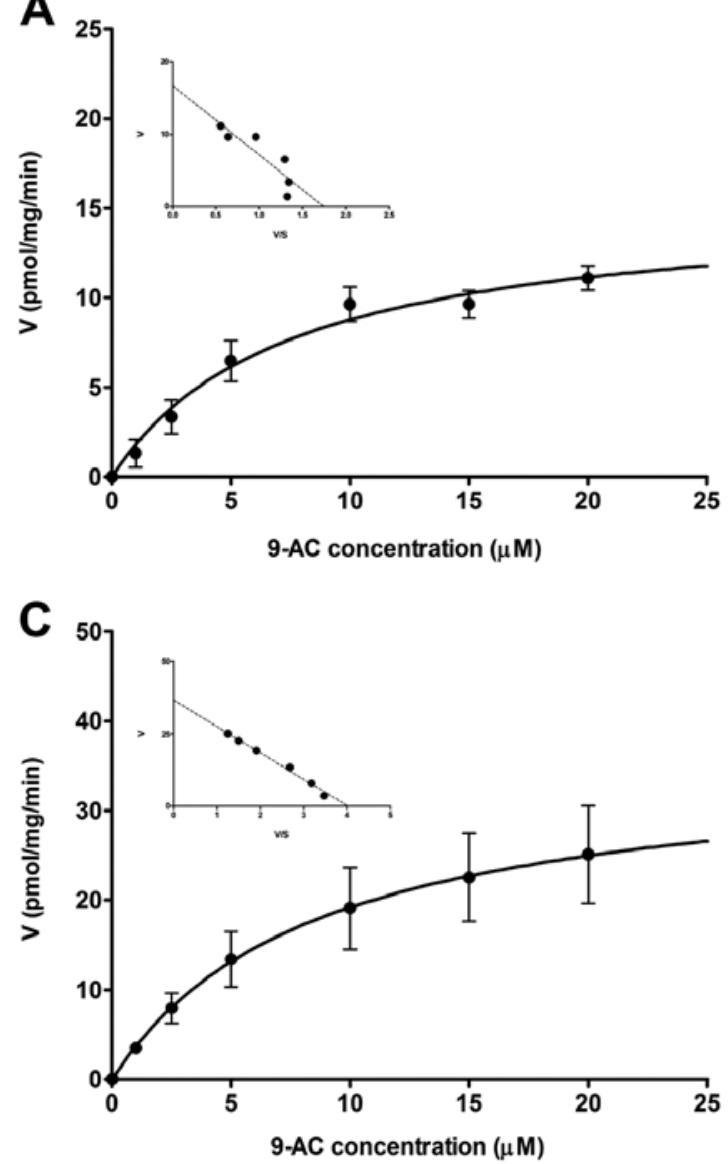

B

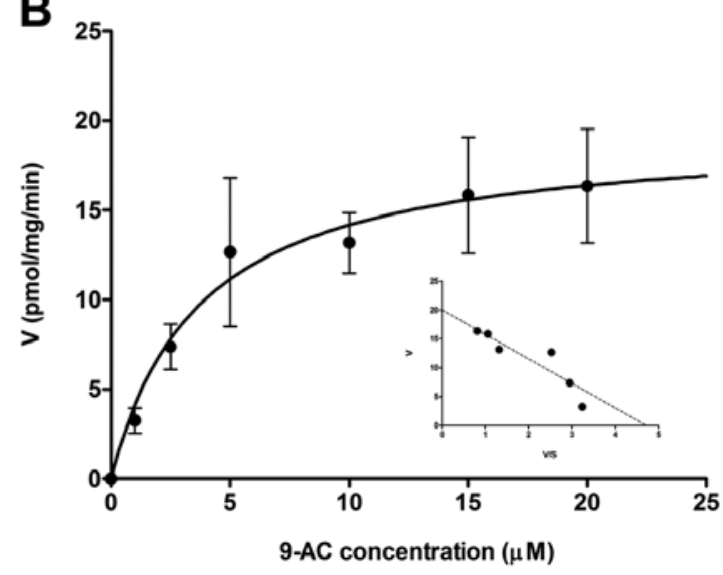

D

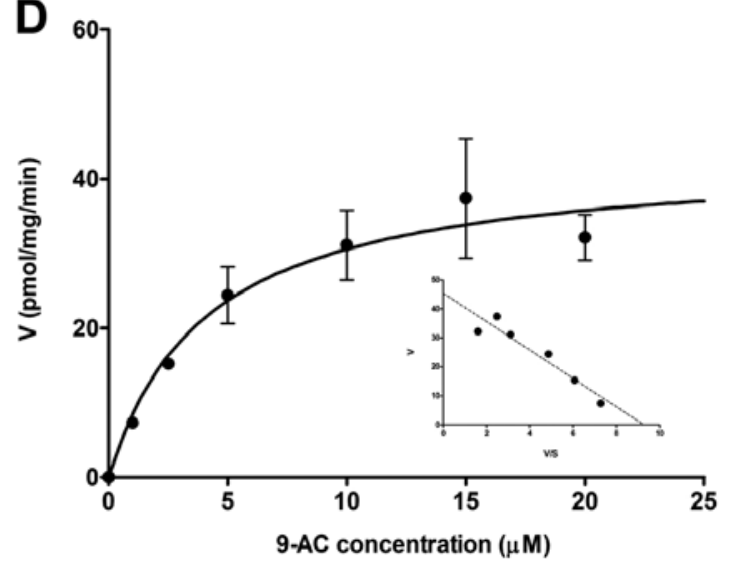

Figure 1. Hepatic formation of 9-AC metabolites. Kinetics of M1 formation in human (A) and rat (B) liver microsomes and of M2 formation in human (C) and rat (D) liver microsomes was assessed after incubation with 9-AC in the presence of NADPH. Eadie-Hofstee plots are shown as insets on each graph. Values are normalized to protein content as a function of 9-AC concentration. Data are expressed as mean \pm SD $(n=3)$.

Table I. Kinetic parameters of the formation of the 9-AC metabolite M1 in human and rat liver microsomes.

\begin{tabular}{cccccc}
\hline & Subject & Model & $\mathrm{V}_{\max }(\mathrm{pmol} / \mathrm{mg} / \mathrm{min})$ & $\mathrm{K}_{\mathrm{m}}(\mu \mathrm{M})$ & $\mathrm{V}_{\max } / \mathrm{K}_{\mathrm{m}}(\mathrm{ml} / \mathrm{min} / \mathrm{mg})$ \\
\hline \multirow{2}{*}{ Human } & 1 & Michaelis-Menten & 13.3 & 7.15 & 1.86 \\
& 2 & Michaelis-Menten & 13.9 & 6.99 & 1.99 \\
& 3 & Michaelis-Menten & 15.7 & 8.22 & 1.91 \\
Rat & 1 & Michaelis-Menten & 26.9 & 4.26 & 6.32 \\
& 2 & Michaelis-Menten & 16.8 & 1.69 & 9.94 \\
& 3 & Michaelis-Menten & 15.7 & 7.14 & 2.20 \\
\hline
\end{tabular}

Table II. Kinetic parameters of the formation of the 9-AC metabolite M2 in human and rat liver microsomes.

\begin{tabular}{lccccc}
\hline & Subject & Model & $\mathrm{V}_{\max }(\mathrm{pmol} / \mathrm{mg} / \mathrm{min})$ & $\mathrm{K}_{\mathrm{m}}(\mu \mathrm{M})$ & $\mathrm{V}_{\max } / \mathrm{K}_{\mathrm{m}}(\mathrm{ml} / \mathrm{min} / \mathrm{mg})$ \\
\hline \multirow{2}{*}{ Human } & 1 & Michaelis-Menten & 48.4 & 7.78 & 4.84 \\
& 2 & Michaelis-Menten & 21.7 & 7.42 & 2.25 \\
& 3 & Michaelis-Menten & 36.1 & 9.89 & 3.65 \\
Rat & 1 & Michaelis-Menten & 43.6 & 4.55 & 9.58 \\
& 2 & Michaelis-Menten & 54.3 & 3.95 & 13.8 \\
& 3 & Michaelis-Menten & 29.5 & 2.65 & 11.1 \\
\hline
\end{tabular}




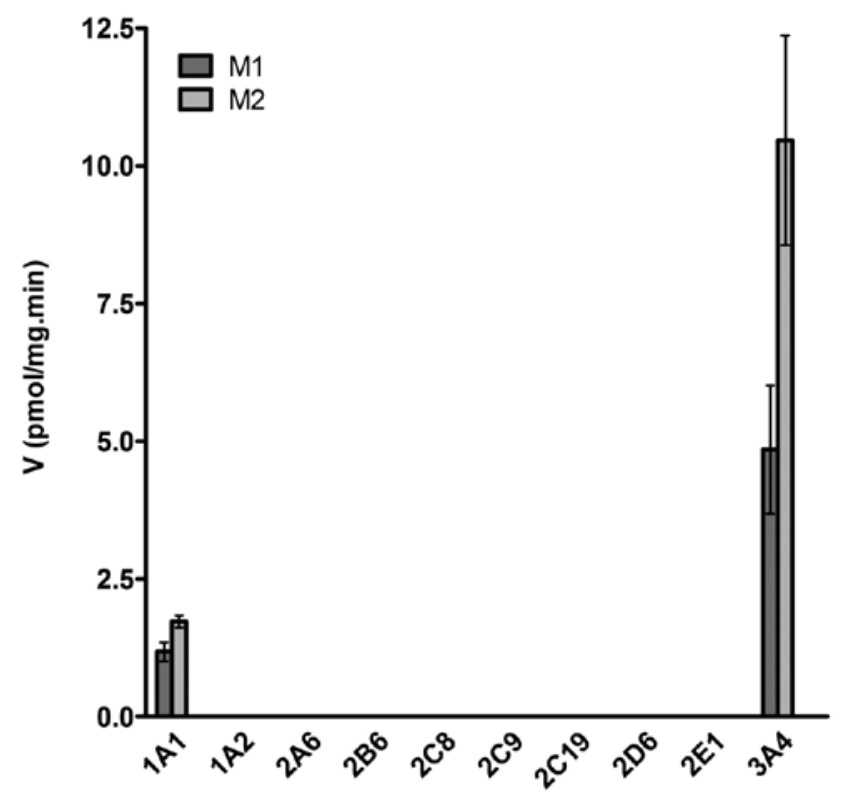

Human recombinant CYPs

Figure 2. Formation of M1 and M2 by human recombinant cytochrome P450 isoforms (CYP). Recombinant human CYPs were incubated with $5 \mu \mathrm{M} 9$-AC in the presence of NADPH and formation rates of the metabolites normalized to protein content as a function of 9-AC concentration. Data are shown as mean $\pm \operatorname{SD}(n=3)$.

Hydroxylation of 9-AC by human CYP enzymes. To investigate the phase I enzymes that are responsible for 9-AC hydroxylation, recombinant human CYP isoenzymes of the families 1 ,
2 and 3, namely 1A1, 1A2, 2A6, 2B6, 2C8, 2C9, 2C19, 2D6, $2 \mathrm{E} 1$ and $3 \mathrm{~A} 4$, were screened using $5 \mu \mathrm{M}$ 9-AC. As shown in Fig. 2, M1 and M2 were exclusively formed by CYP1A1 and 3A4, whereas 1A2, 2A6, 2B6, 2C8, 2C9, 2C19, $2 \mathrm{D} 6$ and 2E1 were inactive. CYP1A1 catalyzed the formation of M1 and M2 to an equal extent $(1.18 \pm 0.17$ pmoles/mg.min and $1.73 \pm 0.11$ pmoles/mg.min, respectively), while formation of M2 was clearly favored by CYP3A4 (4.84 \pm 1.17 pmoles/mg.min and $10.40 \pm 1.91$ pmoles/mg.min, respectively). Based on our data we therefore propose the following CYP-dependent metabolic pathway of 9-AC (Fig. 3).

Drug interactions. We further evaluated the possible interactions of 9-AC with other CYP substrates. 9-AC metabolism was quantified in rat and human liver microsomes, which were preincubated with known CYP inhibitors, namely 7-hydroxy-flavone (CYP1A1), $\alpha$-naphthoflavone (CYP1A1 and 1A2) troleandomycin and ketoconazole (CYP3A4) at increasing concentrations $(0-100 \mu \mathrm{M})$. Pretreatment of human liver microsomes with troleandomycin and ketoconazole led to a severe inhibition of $\mathrm{M} 1$ and $\mathrm{M} 2$ formation with $\mathrm{IC}_{50}$ values of $0.75 \pm 0.09$ and $0.95 \pm 0.12 \mu \mathrm{M}$ for troleandomycin and $0.067 \pm 0.010$ and $0.097 \pm 0.013 \mu \mathrm{M}$ for ketoconazole, respectively. Almost identical $\mathrm{IC}_{50}$ values for $\mathrm{M} 1$ and $\mathrm{M} 2$ inhibition by troleandomycin and ketoconazole were observed in rat liver microsomes (data not shown). Interestingly, pretreatment with $\alpha$-naphthoflavone, which acts as an inhibitor of CYP1A1 and 1A2, but also activates CYP3A4, resulted in an increase of the formation of M1 and M2 by 6.45- and 3.67-fold compared to control in rat and human microsomes. 7-Hydroxy-flavone did not affect 9-AC metabolism.<smiles>CC[C@@]1(O)C(=O)OCc2c1cc1n(c2=O)Cc2cc3c(N)cccc3nc2-1</smiles>

9-AC<smiles>CCC(O)CC(C)(C)CC</smiles>

M2

CYP3A4<smiles>[14CH2][14CH2][14CH3]</smiles>

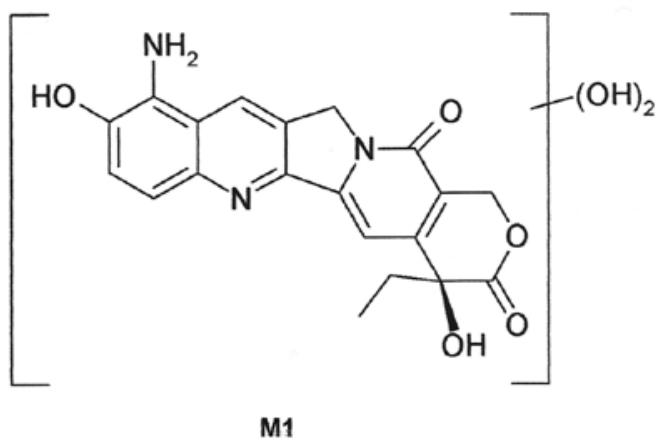

Figure 3. Cytochrome P450-dependent metabolic pathway of 9-AC in human and rat liver. 


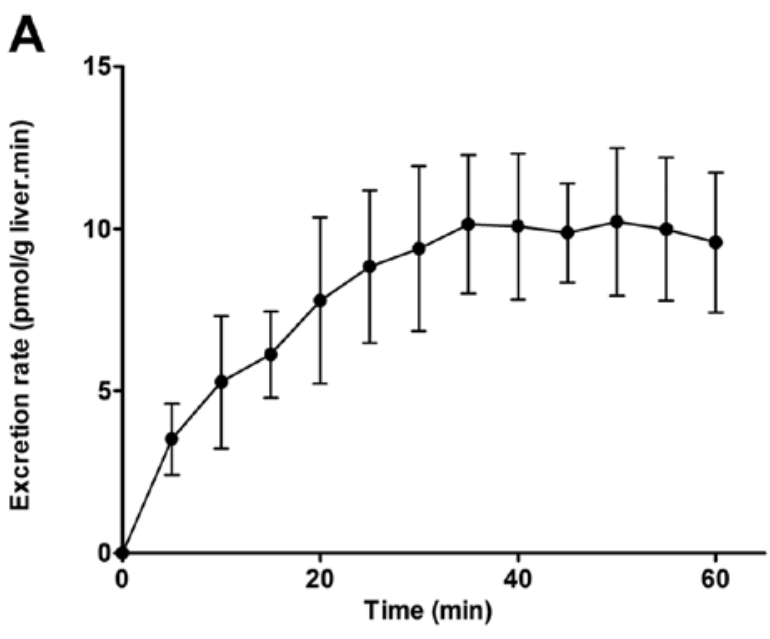

B
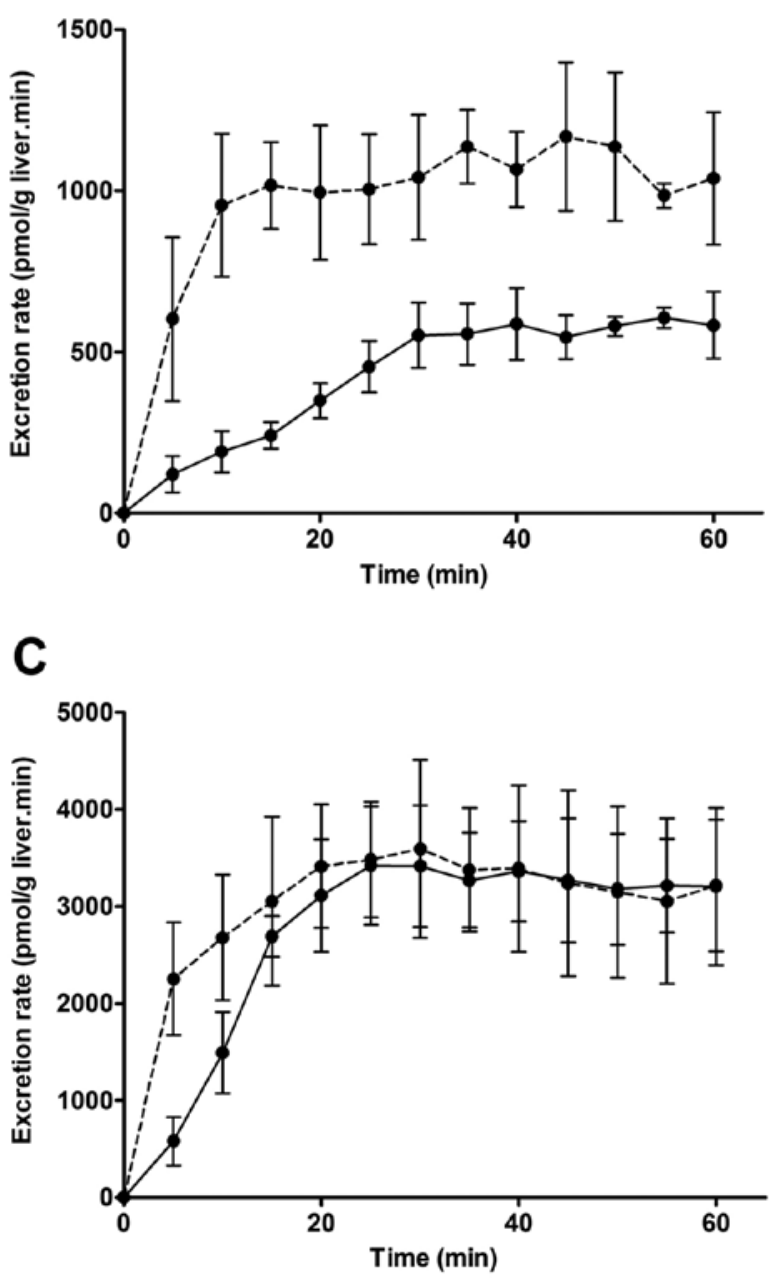

Figure 4. Excretion of 9-AC and its metabolites in the isolated perfused liver of Wistar rats. Time course of the excretion of M1 (A), M2 (B) and 9-AC (C), when $5 \mu \mathrm{M}$ 9-AC were applied to the liver for $60 \mathrm{~min}$. Dotted lines represent efflux into the perfusate; full lines represent biliary excretion. Data are expressed as mean $\pm \operatorname{SD}(n=3)$.

Metabolism and disposition of 9-AC in Wistar rats. An isolated perfused rat liver model was used to determine the hepato-biliary elimination of 9-AC and its biotransformation products. Application of 9-AC $(5 \mu \mathrm{M})$ to the liver of

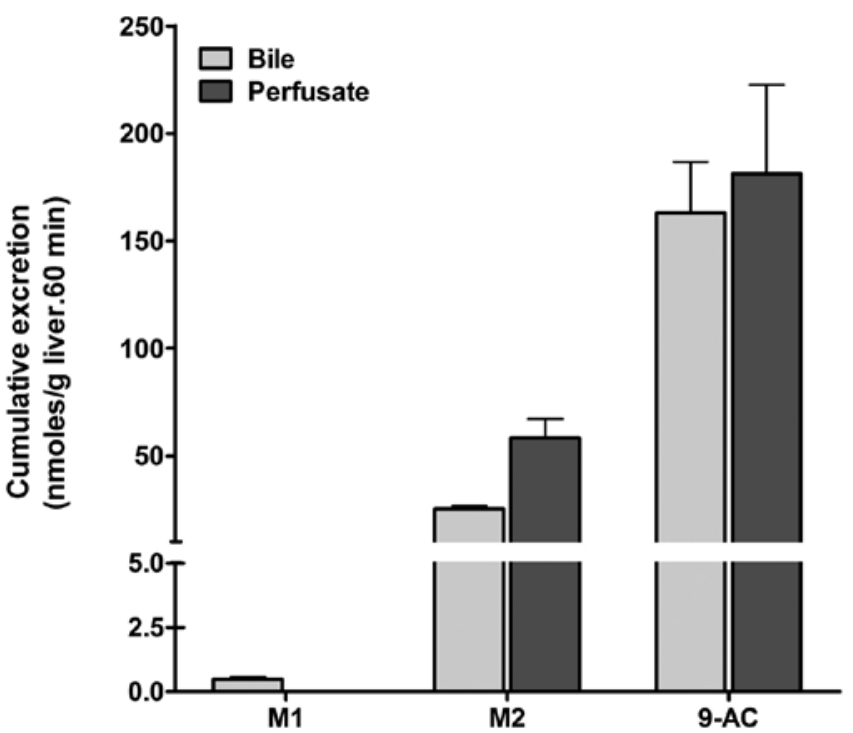

Figure 5. Disposition of M1 and M2 and 9-AC in Wistar rats after $60 \mathrm{~min}$ perfusion with $5 \mu \mathrm{M}$ 9-AC. Data are expressed as mean $\pm \mathrm{SD}(\mathrm{n}=3)$.

Table III. Disposition of 9-AC and its metabolites M1 and M2 in the isolated perfused rat liver of Wistar rats.

\begin{tabular}{lccc}
\hline & $9-\mathrm{AC}$ & $\mathrm{M} 1$ & $\mathrm{M} 2$ \\
\hline $\mathrm{Cl}_{\mathrm{H}}(\mathrm{ml} / \mathrm{min})$ & $25.9 \pm 1.39$ & - & - \\
$\mathrm{F}_{\mathrm{H}}$ & $0.25 \pm 0.05$ & - & - \\
$\mathrm{E}_{\mathrm{H}}$ & $0.75 \pm 0.08$ & - & - \\
$f_{\text {bile }}(\%)$ & $17.66 \pm 2.59$ & $0.05 \pm 0.01$ & $2.75 \pm 0.14$ \\
$f_{\text {perfusate }}(\%)$ & $19.65 \pm 4.47$ & n.d. & $6.30 \pm 0.98$
\end{tabular}

Hepatic clearance $\left(\mathrm{Cl}_{\mathrm{H}}\right)$, hepatic bioavailability $\left(\mathrm{F}_{\mathrm{H}}\right)$, hepatic extraction rate $\left(\mathrm{E}_{\mathrm{H}}\right)$ of $9-\mathrm{AC}$, the amount of $9-\mathrm{AC}$ and its metabolites excreted in bile and perfusate expressed as a percentage of the administered dose. n.d., not detectable.

male Wistar rats moderately stimulated bile flow by $7.8 \%$. Choleresis reached its peak values at 5-10 min after the addition of 9-AC to the perfusion medium (mean maximum value, $0.83 \pm 0.08 \mathrm{mg} / \mathrm{g}$ liver.min), indicating moderate solvent drag by the excretion of $9-\mathrm{AC}$ and its metabolites into the bile. After the initial choleresis, bile flow slowly declined reaching its initial values after $60 \mathrm{~min}$ (data not shown). In addition to the parent drug two metabolites M1 and M2 with identical retention times (as observed in the microsomal samples) could be detected in the bile. However, the levels of M1 that were excreted into the effluent perfusate were below the detection level. The kinetics of the excretion of 9-AC and its metabolites M1 and M2 into the bile and perfusate after the application of $5 \mu \mathrm{M} 9-\mathrm{AC}$ to the rat liver are presented in Fig. 4. Biliary excretion of 9-AC, M1 and M2 plateaued after 25-35 min with average excretion rates of 3420 \pm 613 , $10.1 \pm 2.11$ and $551 \pm 101$ pmoles/g liver.min, respectively. Comparable excretion patterns for 9-AC and M2 were observed for their secretion into the effluent perfusate with 
mean excretion rates of $3592 \pm 914$ and $1167 \pm 230$ pmoles $/ \mathrm{g}$ liver.min, respectively. However, the steady state for efflux into the perfusate was reached after 10-20 min after the application of the drug to the liver.

Biotransformation of 9-AC in the liver of Wistar rats was moderate, amounting to only $9.09 \pm 0.99 \%$ of the drug applied to the liver. Fig. 5 shows the cumulative excretion of $9-\mathrm{AC}$ and its metabolites over a 60 -min period. M1 was clearly the minor product (mean cumulative excretion, $0.48 \pm 0.09 \mathrm{nmoles} / \mathrm{g}$ liver.60 min; $0.05 \pm 0.01 \%$ of applied drug) and was exclusively eliminated via the bile. In comparison, the cumulative excretion of M2 was approximately 200-fold higher, accounting for $9.04 \pm 0.98 \%$ of the applied drug. Efflux of M2 into the perfusate exceeded its biliary excretion $(58.1 \pm 9.01 \mathrm{vs}$. $25.4 \pm 1.30 \mathrm{nmoles} / \mathrm{g}$ liver.60 min). Of the applied dose $37.3 \%$ was eliminated as unchanged 9-AC into the bile and perfusate in equal amounts $(162.3 \pm 23.9$ vs. $181.4 \pm 41.3 \mathrm{nmoles} / \mathrm{g}$ liver after $60 \mathrm{~min}$ ).

Pharmacokinetic parameters describing the disposition of 9-AC in the livers of Wistar rats were determined using data from effluent perfusate samples collected during a 60-min period after the addition of $5 \mu \mathrm{M}$ drug to the perfusion medium. As shown in Table III, 9-AC has a hepatic bioavailability $\left(\mathrm{F}_{\mathrm{H}}\right)$ of $0.25 \pm 0.05$, indicating that approximately $75 \%$ of the parent drug is extracted from the liver within the first pass. Pronounced extraction, therefore, results in a high clearance rate of $25.9 \pm 1.39 \mathrm{ml} / \mathrm{min}$ in Wistar rats.

\section{Discussion}

9-AC is an anticancer agent with pronounced activity against various human cancer cell lines in vitro. To overcome its therapy limiting toxicity and to improve its bioavailability, new formulation and prodrugs of 9-AC were developed and tested with promising results. But although there are numerous studies concerning the pharmacokinetics and the amount of the non-enzymatic hydrolysis of 9-AC, little is known about its enzymatic biotransformation. It is known that metabolism and excretion of drugs, such as the camptothecins, which have steep exposure-response curves and narrow therapeutic indexes, have a strong impact on their systemic exposure. Thus, in the present study, we investigated for the first time the hepatic metabolism and excretion of 9-AC.

Using a sensitive LC/MS/MS system we detected two phase I metabolites M1, dihydroxy-9-AC and M2, monohydroxy-9-AC, in both rat and human liver. Hepatic hydroxylation of 9-AC is in line with literature data as phase I biotransformation has already been reported as the major metabolic pathway for lipophilic camptothecin derivates, such as 10-hydroxycamptothecin (30), irinothecan (31) and topotecan (24). In contrast to other camptothecin derivates, 9-AC and its hydroxylation products did not undergo further phase II conjugation. When we quantified the total amount of 9-AC that is transformed into M1 and M2 by rat and human liver microsomes, we found that rat liver has a significantly higher hydroxylating activity than human one (50\% of the applied dose vs. $24 \%$, respectively). Metabolism, however, is dose-dependent, as a 4-fold increase of 9-AC concentration resulted in a considerable decrease of metabolite formation (only 17 and $11 \%$ of the applied dose was metabolized in human and rat liver microsomes, respectively). Higher enzymatic clearance by rat liver may indeed be an explanation, why the toxicity of 9-AC was significantly lower in the in vitro studies using rat and mouse models than that observed in patients (32).

Hydroxylation of 9-AC is mainly catalyzed by hepatic CYP3A4, which displays large inter-individual differences in both content and catalytic activity in humans (33). Data from phase I pharmacokinetic studies showed significant interpatient variability in the bioavailability of 9-AC $(68.1 \pm 36.4 \%)$ (34), which may be due to alterations in its CYP3A4 catalyzed biotransformation. Furthermore, it was observed that patients receiving phenytoin, carbamazepine, phenobarbital and/or valproic acid had a significantly higher clearance and thus, lower serum concentrations of 9-AC compared with patients who had not been treated with anticonvulsants. Patients treated with anticonvulsants required 3-fold higher doses. However, they experienced milder toxicities (22). The anticonvulsants used in this study are inducers of CYP enzymes and consequently lower the systemic exposure to drugs that are biotransformed by these enzymes (35). Indeed, when human liver microsomes were treated with $\alpha$-naphthoflavone, which acts as CYP1A1 inhibitor and CYP3A4 activator, we observed a significant increase of 9-AC hydroxylation, demonstrating the strong influence of CYP3A4 on 9-AC bioavailability. CYP3A4 activity can be lowered by either co-administration of 3A4-inhibitors or downregulation due to hepatic dysfunction (36), requiring dosage adjustments in patients with liver diseases or patients co-treated with enzyme inhibitors, as reported for irinotecan (37). In the present study, we therefore examined the influence of specific 3A4 inhibitors on 9-AC hydroxylation. Co-treatment of human liver microsomes with troleandomycin and ketoconazole led to a dramatic decrease in the formation of $\mathrm{M} 1$ and $\mathrm{M} 2$. We demonstrated that enzymatic metabolism of 9-AC is strongly affected by alterations in CYP3A4 activity. Similar alterations may have contributed to the lack of patient response observed in clinical trials.

Another isoenzyme that is involved in 9-AC metabolism is the extrahepatic CYP1A1, which is mainly expressed in the lung and the gastrointestinal tract (38). Although the hydroxylation rate is significantly lower than that of CYP3A4, CYP1A1-mediated metabolism may play an important role in patients with CYP1A1 induced status, which includes patients who are smokers (39). Inhibition of CYP3A4 could further lead to a shift in extrahepatic 9-AC hydroxylation catalyzed by CYP1A1 and therefore strongly influence the serum concentrations of the drug. Interestingly, co-administration of specific CYP1A1 inhibitors did not affect 9-AC hydroxylation in human liver microsomes. It is not known yet whether 9-AC metabolites also exhibit anticancer activity or contribute to its toxicity. However, as hydroxylated camptothecins, namely 10-hydroxy-campthothecin, topotecan and SN38 (the active metabolite of irinotecan) (40) are highly active, 9-AC metabolites may also contribute to pharmacological activity.

Furthermore, we investigated biliary elimination of 9-AC and its both metabolites by perfusing isolated male Wistar rat livers using an initial concentration of 9-AC $(5 \mu \mathrm{M})$ that 
corresponds to those encountered in vivo in mice (plasma concentration: about $1 \mu \mathrm{g} / \mathrm{ml}$ at a dose of $1.25 \mathrm{mg} / \mathrm{kg}$ ) (32). Over a 60-min period the perfused liver extracted approximately $75 \%$ of applied 9-AC, resulting in a high hepatic clearance rate of $25.9 \mathrm{ml} / \mathrm{min}$; steady-state concentrations were achieved within $30 \mathrm{~min}$ after the commencement of infusion. Of the administered dose, $17.7 \%$ was found in bile and $19.7 \%$ in the effluent perfusate. Hepatic biotransformation of 9-AC was moderate, amounting to $9.01 \%$ of the applied dose. While the minor metabolite M1 (0.05\% of the applied dose) was exclusively eliminated into the bile, the main biotransformation product M2 was preferentially excreted into the perfusate (6.3\% vs. $2.8 \%$ ). Assuming that the release of 9-AC into the perfusate represents a fraction of total 9-AC that has been taken up by the liver and is then released without biotransformation, we calculated that liver cells still contain more than $53 \%$ of the applied $9-\mathrm{AC}$.

In conclusion, our data show that 9-AC hydroxylation, which is mediated by both CYP3A1 and 3A4, exhibits both concentration and species-dependent differences. Monitoring of the enzymatic biotransformation will be necessary in future studies.

\section{Acknowledgements}

This study was supported by a grant of the Jubiläumsfonds der Österrreichischen Nationalbank (6398 to W.J.).

\section{References}

1. Wall ME, Wani MC, Cook CE, Palmer KH, McPhail AT and Sim GA: Plant antitumor agents. I. The isolation and structure of camptothecin, a novel alkaloidal leukemia and tumor inhibitor from Camptotheca acuminata. J Am Chem Soc 88: 3888-3890, 1966.

2. Ling YH, Perez-Soler R and Tseng MT: Effect of DNA topoisomerase I inhibitor, 10-hydroxycamptothecin, on the structure and function of nuclei and nuclear matrix in bladder carcinoma MBT-2 cells. Anticancer Res 13: 1613-1617, 1993.

3. Liu LF: Biochemistry of camptothecin. In: Camptothecins: New Anticancer Agents. Potmesil M and Pinedo H (eds). CRC Press, Boca Raton, pp9-19, 1995.

4. Pommier Y: Topoisomerase I inhibitors: camptothecins and beyond. Nat Rev Cancer 6: 789-802, 2006.

5. Hickman JA: Apoptosis and chemotherapy resistance. Eur J Cancer 32A: 921-926, 1996.

6. Kingsbury WD, Boehm JC, Jakas DR, et al: Synthesis of watersoluble (aminoalkyl)camptothecin analogues: inhibition of topoisomerase I and antitumor activity. J Med Chem 34: 98-107, 1991.

7. Giovanella BC, Stehlin JS, Wall ME, Wani MC, Nicholas AW, Liu LF, Silber R and Potmesil M: DNA topoisomerase I-targeted chemotherapy of human colon cancer in xenografts. Science 246 : 1046-1048, 1989.

8. Potmesil M, Vardeman D, Kozielski AJ, Mendoza J, Stehlin JS and Giovanella BC: Growth inhibition of human cancer metastases by camptothecins in newly developed xenograft models. Cancer Res 55: 5637-5641, 1995.

9. Vokes EE, Ansari RH, Masters GA, et al: A phase II study of 9-aminocamptothecin in advanced non-small cell lung cancer. Ann Oncol 9: 1085-1090, 1998.

10. Vokes EE, Gordon GS, Rudin CM, et al: A phase II trial of 9-aminocamptothecin (9-AC) as a 120-h infusion in patients with non-small cell lung cancer. Invest New Drugs 19: 329-333, 2001.

11. Pazdur R, Diaz-Canton E, Ballard WP, et al: Phase II trial of 9-aminocamptothecin administered as a 72-h continuous infusion in metastatic colorectal carcinoma. J Clin Oncol 15: 2905-2909, 1997.
12. Pazdur R, Medgyesy DC, Winn RJ, et al: Phase II trial of 9-aminocamptothecin (NSC 603071) administered as a 120-hr continuous infusion weekly for three weeks in metastatic colorectal carcinoma. Invest New Drugs 16: 341-346, 1998.

13. Kraut EH, Balcerzak SP, Young D, O'Rourke MA, Petrus JJ, Kuebler JP and Mayernik DG: Phase II trial of 9-aminocaptothecin in patients with refractory breast cancer. Proc Am Soc Clin Oncol 16: A620, 1997.

14. Gao SQ, Sun Y, Kopecková P, Peterson CM and Kopecek J: Antitumor efficacy of colon-specific HPMA copolymer/ 9-aminocamptothecin conjugates in mice bearing human-colon carcinoma xenografts. Macromol Biosci 9: 1135-1142, 2009.

15. Juan TY, Roffler SR, Hou HS, et al: Antiangiogenesis targeting tumor microenvironment synergizes glucuronide prodrug antitumor activity. Clin Cancer Res 15: 4600-4611, 2009.

16. Prijovich ZM, Chen BM, Leu YL, Chern JW and Roffler SR: Anti-tumour activity and toxicity of the new prodrug 9-aminocamptothecin glucuronide (9ACG) in mice. Br J Cancer 86: 1634-1638, 2002

17. Hinz HR, Harris NJ, Natelson EA and Giovanella BC: Pharmacokinetics of the in vivo and in vitro conversion of 9-nitro-20(S)-camptothecin to 9-amino-20(S)-camptothecin in humans, dogs, and mice. Cancer Res 54: 3096-3100, 1994.

18. Pantazis P, Harris N, Mendoza J and Giovanella B: The role of $\mathrm{pH}$ and serum albumin in the metabolic conversion of 9-nitrocamptothecin to 9-aminocamptothecin by human hematopoietic and other cells. Eur J Haematol 55: 211-213, 1995.

19. Yan Z, Zhu Z, Li K, Chen P, Wang L, Huang C, Xue J and Liu M: A phase I pharmacokinetics study of 9-nitrocamptothecin in patients with advanced solid tumors. Cancer Chemother Pharmacol 67: 955-961, 2011.

20. Gao SQ, Lu ZR, Kopecková P and Kopecek J: Biodistribution and pharmacokinetics of colon-specific HPMA copolymer 9-aminocamptothecin conjugate in mice. J Control Release 117: 179-185, 2007.

21. d'Esposito F, Nebot N, Edwards RJ and Murray M: Impaired irinotecan biotransformation in hepatic microsomal fractions from patients with chronic liver disease. Br J Clin Pharmacol 70: 400-408, 2010.

22. Grossman SA, Hochberg F, Fisher J, et al: Increased 9-aminocamptothecin dose requirements in patients on anticonvulsants. Cancer Chemother Pharmacol 42: 118-126, 1998.

23. Lokiec F, du Sorbier B and Sanderink GJ: Irinotecan (CPT-11) metabolites in human bile and urine. Clin Cancer Res 2: 1943-1949, 1996.

24. Platzer P, Schaden S, Thalhammer T, Hamilton G, Rosenberg B, Silgoner I and Jäger W: Biotransformation of topotecan in the isolated perfused rat liver: identification of three novel metabolites. Anticancer Res 18: 2695-2700, 1998.

25. Jäger W, Correia MA, Bornheim LM, Mahnke A, Hanstein WG, Xue L and Benet LZ: Ethynylestradiol-mediated induction of hepatic CYP3A9 in female rats: implication for cyclosporine metabolism. Drug Metab Dispos 27: 1505-1511, 1999.

26. Bradford MM: A rapid and sensitive method for the quantitation of microgram quantities of protein utilizing the principle of protein-dye binding. Anal Biochem 72: 248, 1976.

27. Thalhammer T, Stapf V, Gajdzik L and Graf J: Bile canalicular cationic dye secretion as a model for P-glycoprotein mediated transport. Eur J Pharmacol 270: 213-220, 1994.

28. Platzer P, Thalhammer T, Hamilton G, Ulsperger E, Rosenberg E, Wissiack R and Jäger W: Metabolism of camptothecin, a potent topoisomerase I inhibitor, in the isolated perfused rat liver. Cancer Chemother Pharmacol 45: 50-54, 2000.

29. Li K, Chen X, Zhong D and Li Y: Identification of the metabolites of 9-nitro-20(S)-camptothecin in rats. Drug Metab Dispos 31: 792-797, 2003.

30. Platzer P, Thalhammer T, Reznicek G, Hamilton G, Zhang R and Jäger W: Metabolism and biliary excretion of the novel anticancer agent 10-hydroxycamptothecin in isolated perfuse rat liver. Int J Oncol 19: 1287-1293, 2001.

31. Farabos C, Haaz MC, Gires P and Robert J: Hepatic extraction, metabolism, and biliary excretion of irinotecan in the isolated perfused rat liver. J Pharm Sci 90: 722-731, 2001

32. Kirstein MN, Houghton PJ, Cheshire PJ, Richmond LB, Smith AK, Hanna SK and Stewart CF: Relation between 9-aminocamptothecin systemic exposure and tumor response in human solid tumor xenografts. Clin Cancer Res 7: 358-366, 2001.

33. Ingelman-Sundberg M: Polymorphism of cytochrome P450 and xenobiotic toxicity. Toxicology 181-182: 447-452, 2002. 
34. Xiong HQ, Tran HT, Madden TL, Newman RA and Abbruzzese JL: Phase I and pharmacological study of oral 9-aminocamptothecin colloidal dispersion (NSC 603071) in patients with advanced solid tumors. Clin Cancer Res 9: 2066-2071, 2003.

35. Yap KY, Chui WK and Chan A: Drug interactions between chemotherapeutic regimens and antiepileptics. Clin Ther 30 1385-1407, 2008.

36. Dresser GK, Spence JD and Bailey DG: Pharmacokineticpharmacodynamic consequences and clinical relevance of cytochrome P450 inhibition. Clin Pharmacokinet 38: 41-57, 2000

37. Kehrer DF, Mathijssen RH, Verweij J, de Bruijn P and Sparreboom A: Modulation of irinotecan metabolism by ketoconazole. J Clin Oncol 20: 3122-3129, 2002.
38. Ding $X$ and Kaminsky LS: Human extrahepatic cytochromes P450: function in xenobiotic metabolism and tissue-selective chemical toxicity in the respiratory and gastrointestinal tracts. Annu Rev Pharmacol Toxicol 43: 149-173, 2003.

39. Dörrenhaus A, Müller T and Roos PH: Increased CYP1A1 expression in human exfoliated urothelial cells of cigarette smokers compared to non-smokers. Arch Toxicol 81: 19-25, 2007.

40. Garcia-Carbonero R and Supko JG: Current perspectives on the clinical experience, pharmacology, and continued development of the camptothecins. Clin Cancer Res 8: 641-661, 2002. 